\title{
THE EFFECT OF BEVACIZUMAB ON ALPHA SMOOTH MUSCLE ACTINEXPRESSION AND FIBROBLAST COUNT TO PREVENT POSTTRABECULECTOMY FIBROSIS IN NEW ZEALAND WHITE RABBIT
}

\author{
${ }^{1}$ Sekar Ayu Sitoresmi, ${ }^{* 1}$ Nurwasis, ${ }^{1}$ Evelyn Komaratih, ${ }^{2}$ Heriyawatih
}

\begin{abstract}
Background, the wound healing process is the most common cause of glaucoma surgery failure that causes the incapability of controlling the intraocular pressure (IOP) and progressive optic nerve damage.

Objective: This study aimed to analyze the effect of Bevacizumab on myofibroblast and fibroblast in trabeculectomy area of rabbit models in order to find a safer wound healing modulator to improve surgical outcomes.
\end{abstract}

Method: Sixteen New Zealand white rabbits aged 4-6 months and weight between2,5-3,5 $\mathrm{kg}$ was performed trabeculectomy on the right eye with postoperative subconjunctival injection of BSS and Bevacizumab. Subjects were put into control and bevacizumab group. Examination were done and subjects were terminated and performed enucleation on postoperative day 14. Samples were histologically stained with Haematoxyline-Eosin to count the fibroblast.

Result: Mann Whitney $u$ test and independent t-test were used to analyse the data. We found both less expression of alpha smooth muscle act in and fibroblast count on bevacizumab group compared to control group which indicates less myofibroblast, fibroblast, and less scarring potential in trabeculectomy area. There is significant decrease in expression of $\alpha$-SMA in bevacizumab group compared to control group $(p=0,0195)$, and with independent t-test we found less fibroblast in bevacizumab group significantly $(p=0,0005)$.

Conclusion: Bevacizumab inhibits fibroblast proliferation and its differentiation to myofibroblast that lead to less collagen production and fibrosis.

Keywords---bevacizumab, fibrosis, glaucoma, post trabeculectomy

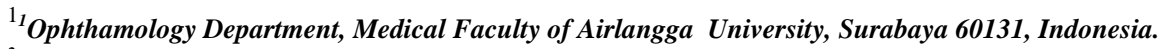

${ }^{2}$ Anatomical Pathology Department, Medical Faculty of Airlangga University, Surabaya 60131, Indonesia.

*Corresponding Author: Dr.Nurwasis dr., Sp.M(K)

Ophthalmology Department, Medical Faculty of Airlangga University, Surabaya 60131, Indonesia.

Email: nurwasisspm@yahoo.com; nurwasis.unair@gmail.com
} 


\section{INTRODUCTION}

Glaucoma is one of the most common causes of blindness throughout the world including Asia (Hong Kong, Japan, and India). The number of glaucoma patients is estimated to be 79,6 millions in 2020, and 50\% of this number is Asian(Quigley and Boman, 2006; Leung, Medeiros and Weinreb, 2008).This disease is caused by a group of optic neuropathies that lead to progressive degeneration of retinal ganglion cells(Leung, Medeiros and Weinreb, 2008). One of the important risk factors for glaucoma is high intraocular pressure (IOP)(Gordon et al., 2003) that is mainly caused by increased resistance to aqueous humor outflow within the conventional outflow pathway (Overby, Stamer and Johnson, 2009; Stamer and Acott, 2012).

Trabeculectomy is the gold standard if medical therapy or laser surgery is incapable of decreasing IOP. The wound healing process of episclera and Tenon's capsule is the most common cause of surgical failure that causes the failure of controlling the IOP and progressive optic nerve damage. Inhibition of fibrosis is important to improve surgical outcome and the popular agents is antimetabolites like mitomycin-C (MMC) and 5-fluorouracyl (5-FU), but the side effects are unfavorable. Antimetabolites can cause nonselective cell death through apoptosis and necrosis, which lead to complications like bleb leak, hypo tony, blebitis, and endophthalmitis. Topical corticosteroids can decrease postoperative IOP but the long-term complications like cataract, secondary infection, herpes activation, and IOP increase is unfavorable for some surgeons. This situation made researchers innovate new agents that are more specific and effective in controlling fibro genesis and have acceptable side effects, one of them is anti vascular endothelial growth factor (anti-VEGF)(Li et al., 2009).

Bevacizumab is monoclonal antibody of nonselective VEGF that inhibits the proliferation of fibroblast mediated by VEGF in vitro. Previous study proved that bevacizumab decreases fibroblast proliferation of Tenon's capsule and induced cell death(O’Neill et al., 2010). Another study stated that VEGF induced myofibroblast transformation post trabeculectomy through transforming growth factor $\beta 1$ (TGF- $\beta 1$ )in rabbit model given VEGF and antiVEGF bevacizumab(Park, Kim and Park, 2013). In this experimental study in rabbits, subconjunctival bevacizumab was injected postoperatively to determine the effect of bevacizumab in inhibition of fibrosis through inhibition of fibroblast proliferation and its differentiation to myofibroblast that is expressed with intraselularalpha smooth muscle act in ( $\alpha$-SMA). Inhibiting subconjunctival fibrosis is expected to increase surgical outcome in postoperative period. This study is aimed to analyse the effect of Bevacizumab on myofibroblast and fibroblast in trabeculectomy area of rabbit models in order to find a safer wound healing modulator to improve surgical outcomes.

\section{METHODS}

This study is a true experimental study with randomized posttest only control group design to evaluate $\alpha$-smooth muscle act in expression and fibroblast count in New Zealand white rabbit(Oryctolagus cuniculus) given subconjunctival injection of bevacizumab post trabeculectomy. This study was conducted in Stem Cell Research and Development Center, Airlangga University, Surabaya. We used 16rabbits aged 4-6 months, male, and weight 2,5-3,5 kg with healthy eyes and bodies. We excluded the subjects with diseases in eyes or bodies, and potential to spread diseases. 
International Journal of Psychosocial Rehabilitation, Vol. 24, Issue 02, 2020

ISSN: $1475-7192$

Rabbits in control group (16 rabbits) was performed trabeculectomy in one eye with subconjunctival injection of BSS $(0,05 \mathrm{~mL})$ and in the bevacizumab group we performed trabeculectomy with subconjunctival injection of 1,25mg/0,05 $\mathrm{mL}$ bevacizumab (Avastin, Genentech.inc). Postoperatively, we examined the IOP and anterior segment of the subjects and the data was recorded at day 1, 7, and 14. We terminated the subjects on day 14postoperative and performed denucleation. Myofibroblast was examined using immunehisto chemistry using alpha smooth muscle actin antibody and scored with immunore active score (IRS). Fibroblast was examined and counted using Hematoxy line-Eosin staining in 5 high power fields.

\section{RESULT}

Statistically using Wilcox on - Mann Whitney U test, we found a significant decrease in expression of $\alpha$-SMA in bevacizumab group compared to control group $(\mathrm{p}=0,0195)$, and with independent $\mathrm{t}$-test we found less fibroblast in bevacizumab group significantly $(\mathrm{p}=0,0005)$. Results can be observed in Table 1 and Table 2.Bleb looked diffuse in the two groups and more a vascular in bevacizumab group.

\section{DISCUSSION}

In this research, histopathologically, we found significant decrease in fibroblast count and $\alpha$-SMA expression that represents myofibroblasts in trabeculectomy site. The decrease in fibroblast and its contractile phenotype (myofibroblast) lead to collagen production decrease that is an important factor to fibrosis. This suggested that even in rabbits with aggressive wound healing response, bevacizumab could give a positive result regarding surgical outcome of trabeculectomy.

Based on histopathology examination, Ozgonul, Mumcuoglu and Gunal stated that inflammation, neovascularization and fibrosis were lower in subconjunctival bevacizumab group. Memarzadeh, et al. found significant scar formation and tissue cellularity in day 10 and 20postoperative in subconjunctival bevacizumab group. Previous study did are search on bevacizumab effectivity in inflammation, angiogenesis, and collagen deposition but they found no significant difference in inflammatory cell reaction but reported less neovascularization and collagen deposition significantly (Li et al., 2009; Memarzadeh et al., 2011; Ozgonul, Mumcuoglu and Gunal, 2014).

Antimetabolites like mitomycin-C(MMC) and 5-FU (5-fluorouracyl) are agents that widely used and reviewed regularly in their role of modulating wound healing in glaucoma surgeries as strong antiproliferatives. An in vitro study stated that 5-FU induce apoptosis, and MMC affects almost every profibrotic process of conjunctival fibroblast. MMC itself is an antibiotic with antiproliferative component. These agents were proved to reduce proliferation, secretion of collagen and also induce apoptosis. MMC also reduce trans differentiation of fibroblast to myofibroblast. Despite of the effectiveness, their usage is limited by the unfavorable side effects (Zada, Pattamatta and White, 2017).

Clinically and experimentally, corticosteroids were proved to reduce local inflammatory response. A prospective study of trabeculectomy with and without postoperative topical prednisolone in 10-year follow-up resulted in lower intraocular pressure, the use of fewer glaucoma medications, and fewer follow-up surgeries compared with standard treatment alone (Breusegem et al., 2010; Ozgonul, Mumcuoglu and Gunal, 2014; Sudiro, 2017; Zada, Pattamatta and White, 2017).The limitation of this study is: (1)observation period did not include other phase of wound healing 
International Journal of Psychosocial Rehabilitation, Vol. 24, Issue 02, 2020

ISSN: $1475-7192$

process; (2)bleb evaluation did not completely performed, (3) subjects were not glaucoma models; (4) not comparing bevacizumab with other wound healing modulators (e.g. MMC and 5-FU).

\section{CONCLUSION}

In conclusion, subconjunctival bevacizumab in postoperative period significantly inhibits fibrosis through decreasing the number of fibroblast and myofibroblast transformation in trabeculectomy site that play a great role in improving surgical outcome.

\section{REFERENCE}

[1] Breusegem, C. et al. (2010) 'Pre- operative nonsteroidal antiinflammatory drug or steroid and outcomes after trabeculectomy: a randomized controlled trial', Ophthamology, 117, pp. 1324-1330.

[2] Gordon, M. et al. (2003) 'The ocular hypertension treatment study: baseline factors that predict the onset of primary open-angle glaucoma', Arch Ophthalmol., 120(4), pp. 16-7.

[3] Leung, E., Medeiros, F. and Weinreb, R. (2008) 'Prevalence of ocular surface disease in glaucoma patients', J Glaucoma, 17, pp. 350-355.

[4] Li, Z. et al. (2009) 'Inhibition of vascular endothelial growth factor reduces scar formation after glaucoma filtration surgery', Invest Ophthalmol Vis Sci, 50, pp. 5217-5225.

[5] Memarzadeh, F. et al. (2011) 'Postoperative Use of Bevacizumab as an Antifibrotic Agent in Glaucoma Filtration Surgery in the Rabbit', Invest Ophthalmol Vis Sci, 50, pp. 3233-3237.

[6] O'Neill, E. et al. (2010) 'Antifibrotic activity of bevacizumab on human Tenon's fibroblasts in vitro', Invest Ophthalmol Vis Sci, 51, pp. 6524-6532.

[7] Overby, D., Stamer, W. and Johnson, M. (2009) 'The changing paradigm of outflow resistance generation: towards synergistic models of the JCT and inner wall endothelium', Exp Eye Res, 88(4), pp. 656-70.

[8] Ozgonul, C., Mumcuoglu, T. and Gunal, A. (2014) 'The Effect of Bevacizumab on Wound Healing Modulation in an Experimental Trabeculectomy Model’, Current Eye Research, 39(5), pp. 451-459.

[9] Park, H., Kim, J. and Park, C. (2013) 'VEGF induces TGF-beta1 expression and myofibroblast transformation after glaucoma surgery', Am J Pathol, 182, pp. 2147-2154.

[10] Quigley, H. and Boman, A. (2006) 'The number of people with glaucoma worldwide in 2010 and 2020', Br J Ophthalmol, 90(3), pp. 262-7.

[11] Stamer, W. and Acott, T. (2012) 'Current understanding of conventional outflow dysfunction in glaucoma’, Curr Opin Ophthalmol, 23(2), pp. 135-43.

[12] Sudiro, D. (2017) Effect of Triamcinolone acetonide on TGF- $\beta$ expression post-trabeculectomy (Experimental Study on Oryctolagus cuniculus). Faculty of Medicine/ Dr. Soetomo General Hospital Surabaya.

[13] Zada, M., Pattamatta, U. and White, A. (2017) 'Modulation of Fibroblasts in Conjunctival Wound Healing', Ophthalmology, 12, pp. 1-14. 
International Journal of Psychosocial Rehabilitation, Vol. 24, Issue 02, 2020

ISSN: $1475-7192$

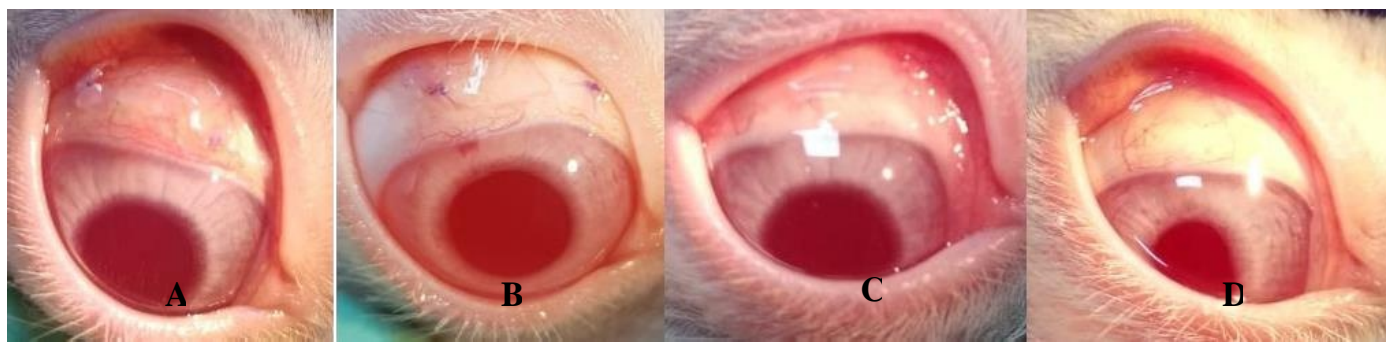

Figure 1:Bleb evaluation day 7: A. control group; B. bevacizumab group; and day 14:C.control group; D. bevacizumab group.

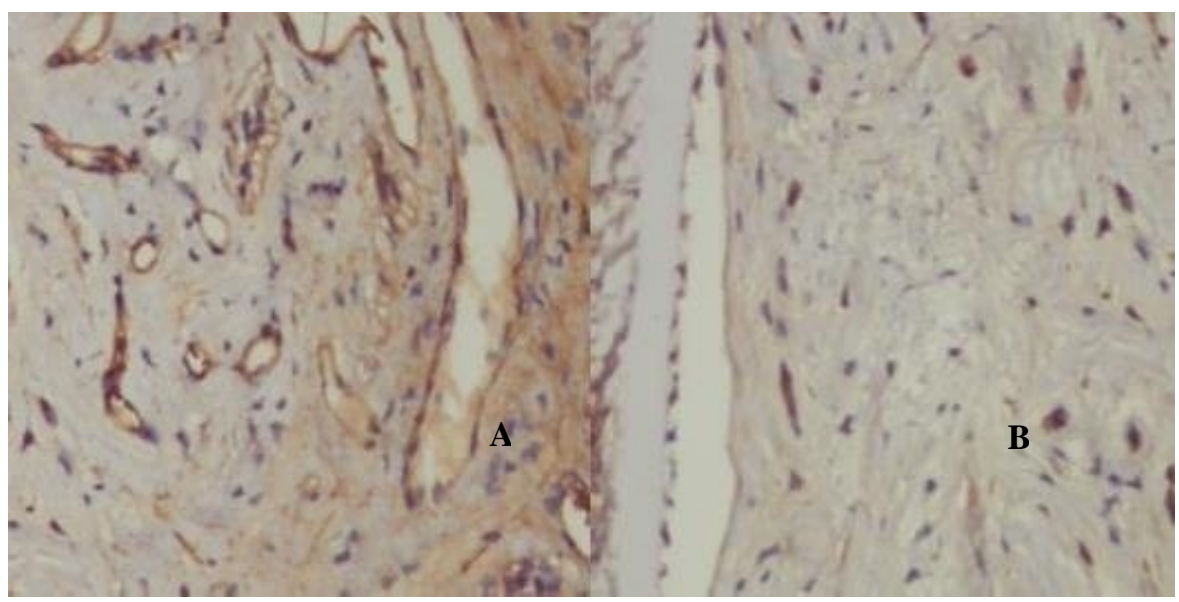

Figure 2:Alpha SMA expression in: A.

control group; B.Bevacizumab group

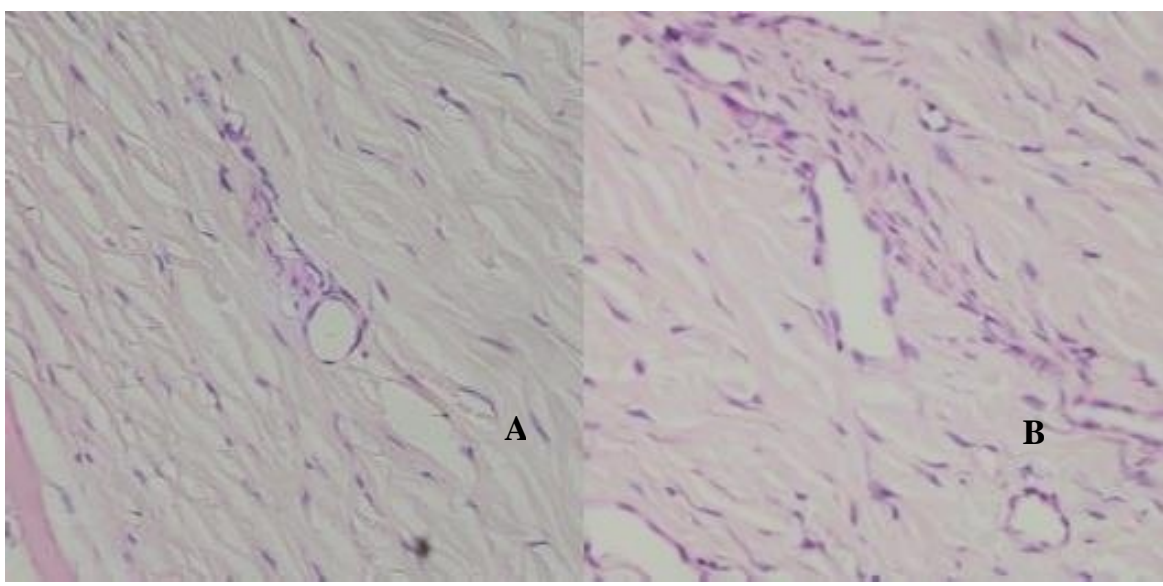

Figure 3:Fibroblast count in: A. control

group; B.Bevacizumab group

Table 1.Alpha SMA in control group and bevacizumab group 
International Journal of Psychosocial Rehabilitation, Vol. 24, Issue 02, 2020

ISSN: 1475-7192

\begin{tabular}{|c|c|c|c|c|c|c|}
\hline \multirow[b]{2}{*}{ Groups } & \multirow[b]{2}{*}{$\mathbf{n}$} & \multicolumn{4}{|c|}{$\alpha$-SMA expression (IRS) } & \multirow{2}{*}{$\begin{array}{l}\text { Wilcoxon - Mann } \\
\text { Whitney test (p1- } \\
\text { tailed) }\end{array}$} \\
\hline & & $\begin{array}{l}\text { Media } \\
\text { n }\end{array}$ & IQD & Min & Max & \\
\hline Control & 8 & 5.0 & 1.5 & 2 & 6 & \multirow[t]{2}{*}{ 0.0195* } \\
\hline Bevacizumab & 8 & 2.5 & 1.0 & 1 & 6 & \\
\hline
\end{tabular}

Significant at $\alpha=0.05(\mathrm{p}<0.05)$

Table 1: Alpha SMA in control group and bevacizumab group

\begin{tabular}{|c|c|c|c|c|c|c|}
\hline \multirow{2}{*}{ Groups } & \multirow{2}{*}{$\mathbf{n}$} & \multicolumn{4}{|c|}{$\alpha$-SMA expression (IRS) } & \multirow{2}{*}{$\begin{array}{l}\text { Independent t-test } \\
\text { (p1-tailed) }\end{array}$} \\
\hline & & Mean & SD & Min & Max & \\
\hline Control & 8 & 40.48 & 2.66 & $\begin{array}{l}36.2 \\
0\end{array}$ & $\begin{array}{ll} & 45.0 \\
& \end{array}$ & \multirow[t]{2}{*}{$0.0005 *$} \\
\hline Bevacizumab & 8 & 34.78 & 2.81 & $\begin{array}{ll} & 31.8 \\
0 & \end{array}$ & $\begin{array}{ll} & 39.2 \\
0 & \end{array}$ & \\
\hline
\end{tabular}

Significant at $\alpha=0.05(\mathrm{p}<0.05)$ 